\title{
Mortalin is a prognostic factor of gastric cancer with normal p53 function
}

\author{
Koji Ando $\cdot$ Eiji Oki $\cdot$ Yan Zhao $\cdot$ Ayae Ikawa-Yoshida \\ Hiroyuki Kitao $\cdot$ Hiroshi Saeki $\cdot$ Yasue Kimura $\cdot$ Satoshi Ida • \\ Masaru Morita · Tetsuya Kusumoto • Yoshihiko Maehara
}

Received: 31 January 2013/Accepted: 11 June 2013/Published online: 5 July 2013

(c) The International Gastric Cancer Association and The Japanese Gastric Cancer Association 2013

\begin{abstract}
Background Mortalin is a heat-non-inducible member of the heat shock protein 70 family. Mortalin binds to p53 and prevents p53 from entering the nucleus. To understand the significance of mortalin in gastric cancer, we investigated the expression of mortalin and p53.

Methods Expression of mortalin and p53 was examined by immunohistochemical staining of 182 clinical samples of gastric cancer.

Results Mortalin-positive and aberrant p53-positive tumors were found in 75.2 and $49.5 \%$ of cases, respectively. Mortalin-positive tumors were deeper in invasion and had more lymph node and liver metastases compared with mortalin-negative tumors $(P<0.01, \quad P<0.05$, respectively). Mortalin-positive tumors had worse prognosis compared with mortalin-negative tumors $(P=0.035)$. Moreover, in tumors with normal p53 function, mortalinpositive tumors had worse prognosis compared with mortalin-negative tumors $(P=0.017)$.

Conclusions Mortalin has a great impact on gastric cancer with normal p53. Therefore, mortalin is a target molecule for treatment of gastric cancer, as well as a promising prognostic factor, especially in tumors with normal p53.
\end{abstract}

K. Ando · E. Oki $(\bowtie) \cdot$ Y. Zhao · A. Ikawa-Yoshida .

H. Saeki · Y. Kimura · S. Ida · M. Morita - T. Kusumoto ·

Y. Maehara

Department of Surgery and Science, Graduate School of Medical

Sciences, Kyushu University, 3-1-1 Maidashi,

Higashi-ku, Fukuoka, Fukuoka 821-8582, Japan

e-mail: okieiji@surg2.med.kyushu-u.ac.jp

H. Kitao

Department of Molecular Oncology, Graduate School of Medical Sciences, Kyushu University, 3-1-1 Maidashi, Higashi-ku, Fukuoka, Fukuoka 821-8582, Japan
Keywords Mortalin $\cdot$ p53 $\cdot$ Prognostic factor

\section{Introduction}

Gastric cancer still has the highest morbidity rate and the second highest mortality rate in Asian countries. Chemotherapy confers only a minimal survival advantage; therefore, the prognosis of patients with advanced or recurrent gastric cancer remains poor. Also, at present, there are few molecular therapies for gastric cancer. Studying the mechanisms and underlying molecules that drive gastric cancer malignancy could contribute to finding a treatment for the disease.

Mortalin was first cloned as a mortality factor in the cytoplasmic fraction of normal, but not in immortal, mouse fibroblasts [1]. Two forms of murine mortalin have been found, mot-1 and mot-2, which differ by two amino acids [2]. Mot-1 is pancytosolic and its overexpression induces cellular senescence, whereas mot-2 is located in the perinuclear region and its overexpression induces malignant transformation. Genetic cloning has not revealed the existence of more than one human mortalin cDNA. Human mortalin has been found to have transforming activity similar to that of murine mot-2 [3]. Mortalin is known to be expressed in various stress responses such as glucose deprivation, low-dose ionising radiation, and caloric restriction [4-6]. Also, mortalin binds to many proteins [79], including tumor suppressor p53. Mortalin sequesters p53 in the cytoplasm and inhibits its normal transcriptional activation $[10,11]$. Mortalin and p53 form a complex in the cytoplasm or in the centrosome, which also compromises p53 activity, and thus prevents apoptosis under stress conditions. It has also been reported that upregulation of mortalin contributes to human carcinogenesis [12]. By 
contrast, downregulation of mortalin results in growth arrest in immortalized human cells [13]. Mortalin seems to be important for cancer cells in carcinogenesis and proliferation. In colorectal cancer, overexpression of mortalin is correlated with poor outcome [14].

However, to date, no studies have shown the relationship between mortalin and p53 expression in human cancer. Here, we report the significance of mortalin in normal p53-expression gastric cancer by analyzing clinical samples.

\section{Materials and methods}

Tissue samples

This study included 182 unselected Japanese patients with primary gastric cancer. All of the patients underwent gastrectomy between 1994 and 2006 at the Department of Surgery and Science, Graduate School of Medical Sciences, Kyushu University Hospital, Fukuoka, Japan. One hundred eighteen men and 64 women were included, ranging from 29 to 90 years of age (mean, 63.8 years). Informed consent was obtained from all patients, and those who did not agree to the study were excluded. A thorough histological examination was carried out with hematoxylinand-eosin-stained tissue preparations, and classification was made according to the general rules established by the Japanese Gastric Cancer Association [15]. No patients who were treated preoperatively with cytotoxic drugs were included in this study.

Immunohistochemical staining of mortalin and p53

Formalin-fixed, paraffin-embedded tissue specimens were used for immunohistochemical staining. A paraffin block contained both cancerous and adjacent non-cancerous tissue, and cancerous tissue that invaded the deepest area of the stomach wall was selected in all cases. Sections $5 \mu \mathrm{m}$ thick from paraffin-embedded blocks were deparaffinised in xylene and rehydrated in a graded series of ethanol. Procedures for immunohistochemical staining have been described previously [14]. The sections were pretreated with autoclaving at $121{ }^{\circ} \mathrm{C}$ for $15 \mathrm{~min}$ in $0.01 \mathrm{~mol} / \mathrm{l}$ citratebuffered saline (pH 6.0) for antigen retrieval. Endogenous peroxidase activity was blocked by incubation with $3 \%$ $\mathrm{H}_{2} \mathrm{O}_{2}$ for 30 min at room temperature. The sections were incubated with $10 \%$ normal goat serum for $1 \mathrm{~h}$ to block non-specific binding of the immunological reagents. After incubation with mouse monoclonal antibodies against mortalin (Clone JG1, 1:50; Affinity BioReagents, Golden, CO, USA) at $4{ }^{\circ} \mathrm{C}$ overnight, streptavidin-biotin complex and horseradish peroxidase were applied, and reaction products were visualized using the Histofine SAB-PO (M) immunohistochemical staining kit (Nichirei, Tokyo, Japan), according to the manufacturer's instructions. The peroxidase labeling was developed by incubation of the sections in diaminobenzidine tetrahydrochloride for $3 \mathrm{~min}$. Finally, nuclear counterstaining was done using Mayer's hematoxylin solution. Two blinded observers (K.A. and Y.Z.) independently examined the immunostained sections. When $>70 \%$ of cytoplasmic-stained cancer cells were included in the section, the tumor was considered to be mortalin-positive.

Expression of p53 was investigated using a monoclonal antibody against p53 (Clone DO-7; Dako Cytomation, Glostrup, Denmark) in the consecutive sections that were used for mortalin staining. The specimens were incubated overnight with a 1:100 dilution of primary antibody at $4{ }^{\circ} \mathrm{C}$. When $70 \%$ or more cancer cells showed positive nuclear staining, then aberrant "positive" staining was defined $[16,17]$. And for the rest cases, aberrant "negative" was defined.

The TP53 gene mutation analysis

The TP53 gene, exon 5 to exon 9 including exon-intron junctions, were amplified by PCR using "p53 primers" (Nippon Gene, Tokyo, Japan) and Ex Taq DNA polymerase with $3^{\prime}$ exonuclease activity (TaKaRa Bio Inc., Tokyo, Japan). The PCR products were purified and used as templates for cycle sequencing reactions with Big Dye Terminator Cycle Sequencing Kit Version 1.0 (Applied Biosystems). Mutations found in a PCR product were verified by reverse sequencing and reconfirmed in two independently amplified PCR products.

Statistical analysis

Statistical analysis was performed by using JMP 6.0 software (SAS institute, Cary, NC, USA). The $\chi^{2}$ test, Fisher's exact test, and one-way ANOVA were used as appropriate. A $P$ value $<0.05$ was considered significant. Kaplan-Meier analysis was used for overall survival. For multivariate analysis, Cox regression analysis was performed using the factors that were significant for overall survival.

\section{Results}

Expression of p53 in gastric cancer

It is widely recognized that, in tumors with TP53 gene mutation, overexpression of aberrant p53 can be stained immunohistochemically [18]. Consistent with previous studies, the expression of positive aberrant p53 was seen in 
Fig. 1 Expression of aberrant p53 and mortalin in gastric cancer. a Staining pattern of tumors with aberrant p53 (magnification, $\times 400$ ). Aberrant p53 can be seen in the nuclei. b Staining pattern of tumors with mortalin expression (magnification, $\times 400$ ). Mortalin can be seen in the cytoplasm. Staining pattern of aberrant $\mathrm{p} 53$ (c) and mortalin (d) in consecutive sections of the same sample. Mortalin-positive tumor cells expressed aberrant p53
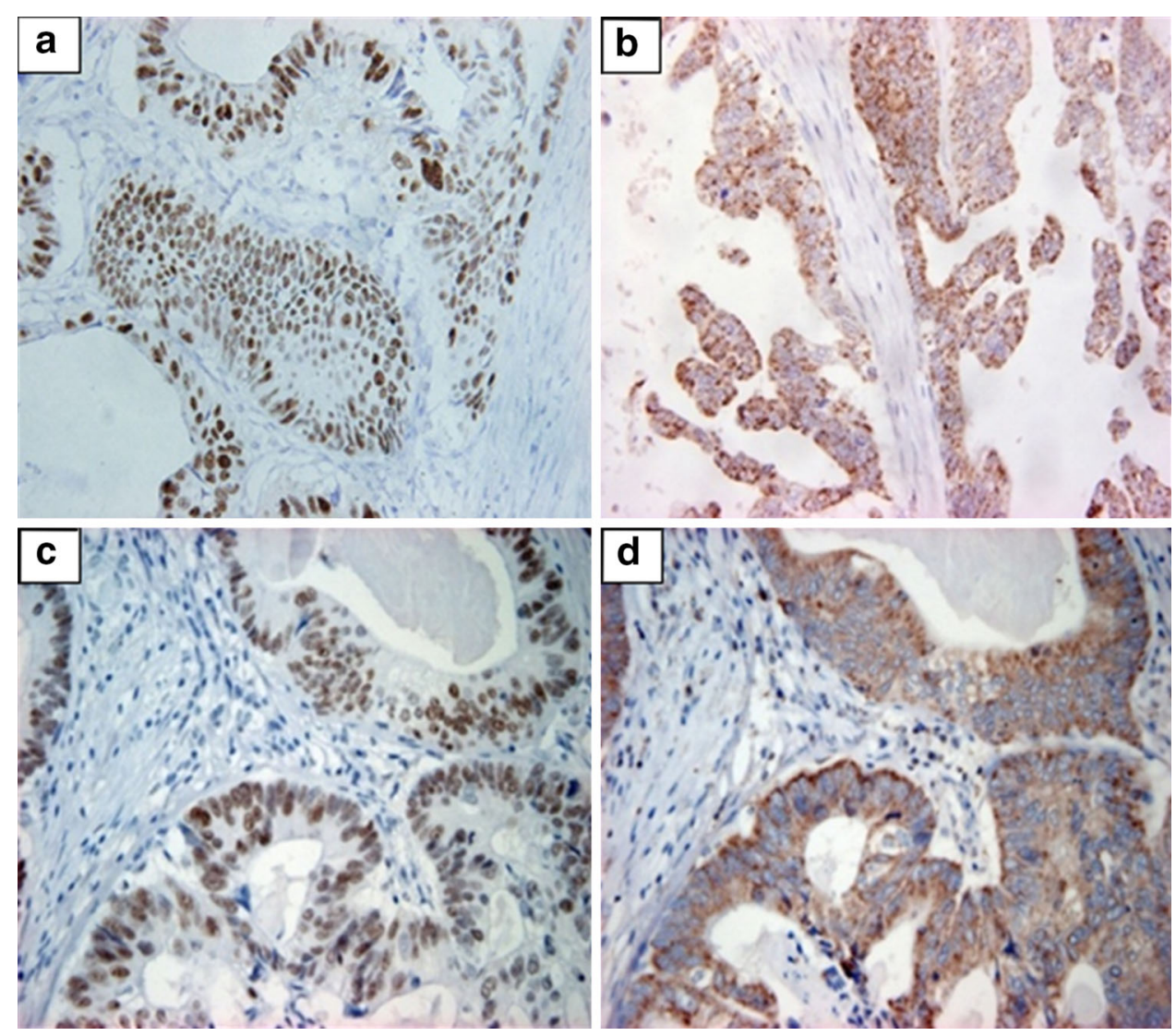

the nuclei of tumor cells (Fig. 1a) [16, 17]. Of 182 tumors, $90(49.5 \%)$ had positive expression of aberrant p53. With clinicopathological analysis (Table 1), aberrant p53-positive tumors had deeper invasion $(P<0.05)$. In addition, aberrant p53 positive tumors had more lymph node and liver metastases compared with tumors with negative aberrant p53 staining $(P<0.01, P=0.001$, respectively). Also, more vascular involvement was seen in aberrant p53positive tumors $(P<0.01)$. Figure 2 a shows the overall survival curve in 182 gastric cancer patients in accordance with p53 expression. As previously reported [19], aberrant p53-positive tumors had worse prognosis than those with aberrant p53-negative tumors $(P=0.043)$.

Significance of p53 immunohistochemistry staining in gastric cancer

To validate whether p53 immunohistochemistry staining reflects the function of $\mathrm{p} 53$, we then checked the relation between p53 immunohistochemistry staining and TP53 gene mutation analysis. According to a report on p53 immunohistochemistry staining in colorectal cancer [17], we re-evaluated p53 staining in three groups. When no cancer cells showed positive nuclear staining, then "null" staining was defined (Fig. 3a). When 10-50\% cancer cells showed positive nuclear staining and sporadic staining of p53, then "scattered" staining was defined (Fig. 3b). When $70 \%$ or more cancer cells showed positive nuclear staining, then "aberrant positive" staining was defined (Fig. 3c).

TP53 gene mutation analysis was done in 90 cases of gastric cancer cases; 17 cases $(18.8 \%)$ had mutation in TP53 gene.

Interestingly, all cases of the scattered staining were TP53 gene wild type (Table 2). Quite a lot of TP53 gene mutant cases had aberrant p53 staining (11/17).

From these results, "scattered" staining of p53 may reflect normal function of $\mathrm{p} 53$.

Mortalin expression is associated with malignant features in gastric cancer

We then confirmed mortalin expression in consecutive sections of gastric cancer samples that were examined for expression of p53. Mortalin was expressed in the cytoplasm (Fig. 1b), and only the tumor cells expressed mortalin.

Of 182 tumors, 137 (75.2\%) were positive for mortalin staining. Table 1 shows the relationship between the clinicopathological features and mortalin expression in gastric cancer patients. Mortalin-positive tumors showed deeper invasion than mortalin-negative tumors $(P<0.01)$. 
Table 1 p53 or mortalin expression and clinicopathological factors in gastric cancer patients

\begin{tabular}{|c|c|c|c|c|c|c|}
\hline \multirow[t]{2}{*}{ Factors } & \multicolumn{2}{|l|}{ p53 expression } & \multirow[t]{2}{*}{$P$ value } & \multicolumn{2}{|l|}{ Mortalin expression } & \multirow[t]{2}{*}{$P$ value } \\
\hline & Negative $(n=92)$ & Positive $(n=90)$ & & Negative $(n=45)$ & Positive $(n=137)(\%)$ & \\
\hline Age $($ mean \pm SD) & $64.2 \pm 12.4$ & $63.4 \pm 11.9$ & 0.61 & $61.9 \pm 13.3$ & $64.5 \pm 11.7$ & 0.87 \\
\hline \multicolumn{7}{|l|}{ Gender } \\
\hline Male & $59(64.1)$ & $59(65.6)$ & \multirow[t]{2}{*}{0.84} & $28(62.2)$ & $90(65.7)$ & \multirow[t]{2}{*}{0.67} \\
\hline Female & $33(35.9)$ & $31(34.4)$ & & $17(37.8)$ & $47(34.3)$ & \\
\hline \multicolumn{7}{|l|}{ Differentiation } \\
\hline Differentiated & $36(39.1)$ & $44(49.4)$ & \multirow[t]{2}{*}{0.16} & $18(40.0)$ & $62(45.6)$ & \multirow[t]{2}{*}{0.51} \\
\hline Undifferentiated & $56(60.9)$ & $45(50.6)$ & & $27(60.0)$ & $74(54.4)$ & \\
\hline \multicolumn{7}{|c|}{ Vascular involvement } \\
\hline V0 & $57(62.0)$ & $59(52.2)$ & \multirow[t]{4}{*}{$0.004 *$} & $27(61.4)$ & $75(54.7)$ & \multirow[t]{4}{*}{0.12} \\
\hline V1 & $26(28.3)$ & $27(23.9)$ & & $12(27.3)$ & $32(23.4)$ & \\
\hline $\mathrm{V} 2$ & $8(8.7)$ & $18(15.9)$ & & $5(11.3)$ & $21(15.3)$ & \\
\hline V3 & $1(1.0)$ & $9(8.0)$ & & $0(0)$ & $9(6.6)$ & \\
\hline \multicolumn{7}{|c|}{ Lymphatic involvement } \\
\hline Ly0 & $31(33.7)$ & $19(21.4)$ & \multirow[t]{4}{*}{0.14} & 17 (38.6) & $33(24.1)$ & \multirow[t]{4}{*}{0.28} \\
\hline Lyl & $20(21.7)$ & $26(29.1)$ & & $8(18.2)$ & $38(27.7)$ & \\
\hline Ly2 & $28(30.4)$ & $24(27.0)$ & & $12(27.3)$ & $40(29.2)$ & \\
\hline Ly3 & $13(14.1)$ & $20(22.5)$ & & $7(15.9)$ & $26(19.0)$ & \\
\hline \multicolumn{7}{|l|}{ Depth of invasion } \\
\hline M, SM & $16(17.4)$ & $6(6.7)$ & \multirow[t]{2}{*}{$0.02 * *$} & $11(24.4)$ & $11(8.0)$ & \multirow[t]{2}{*}{$0.006^{*}$} \\
\hline MP, SS, SE, SI & 76 (82.6) & $84(93.3)$ & & $34(75.6)$ & $126(92.0)$ & \\
\hline \multicolumn{7}{|c|}{ Lymph node metastasis } \\
\hline Negative & $38(41.3)$ & $20(22.2)$ & \multirow[t]{2}{*}{$0.005^{*}$} & $21(46.7)$ & $37(27.0)$ & \multirow[t]{2}{*}{$0.016^{* *}$} \\
\hline Positive & $54(58.7)$ & $70(77.8)$ & & $24(53.3)$ & $100(73.0)$ & \\
\hline \multicolumn{7}{|l|}{ Liver metastasis } \\
\hline Negative & $92(100)$ & $82(92.1)$ & \multirow[t]{2}{*}{$0.001 *$} & $44(100)$ & $130(94.9)$ & \multirow[t]{2}{*}{$0.046^{* *}$} \\
\hline Positive & $0(0)$ & $7(7.9)$ & & $0(0)$ & $7(5.1)$ & \\
\hline \multicolumn{7}{|l|}{ Stage } \\
\hline $\mathrm{I}+\mathrm{II}$ & $46(50.0)$ & $36(40.0)$ & \multirow[t]{2}{*}{0.17} & $25(55.6)$ & $57(41.6)$ & \multirow[t]{2}{*}{0.1} \\
\hline III + IV & $46(50.0)$ & $54(60.0)$ & & $20(44.4)$ & $80(58.4)$ & \\
\hline
\end{tabular}

$M$ mucosa, $S M$ submucosa, $M P$ muscularis propria, $S S$ subserosa, $S E$ penetration of serosa, $S I$ invasion of adjacent structures

$* P<0.01$

$* * P<0.05$

Furthermore, mortalin-positive tumors had more lymph node and liver metastases compared with mortalin-negative tumors $(P<0.05)$. As shown in Fig. $2 \mathrm{~b}$, mortalin-positive tumors had worse prognosis compared with mortalin-negative tumors $(P=0.023)$.

Expression of mortalin and aberrant p53 are significantly related

We examined whether there was a correlation between mortalin and aberrant p53 expression. As shown in Table 3, mortalin and aberrant p53 expression had a significant relationship: tumors that were positive for mortalin also expressed aberrant p53 $(P<0.001)$. Surprisingly, in tumors with expression of aberrant p53 and mortalin, the positively stained cells were exactly the same (Fig. 1c, d), but the proteins were not co-localized in the cells. This was true for all the tumors with co-expression of mortalin and aberrant p53.

Expression of mortalin contributes to malignancy and poor prognosis in tumors with scattered p53 staining

To establish the significance of mortalin, we examined its expression in 75 tumors with scattered staining of p53. As previously mentioned scattered staining of p53 may reflect normal p53 function in gastric cancer (Table 2). 
In 75 tumors, 27 were mortalin-negative and 48 were mortalin-positive. With clinicopathological analysis (Table 4), mortalin-positive tumors showed deeper invasion $(P<0.05)$ compared with mortalin-negative tumors. Among these, mortalin-positive tumors $(n=48)$ had worse
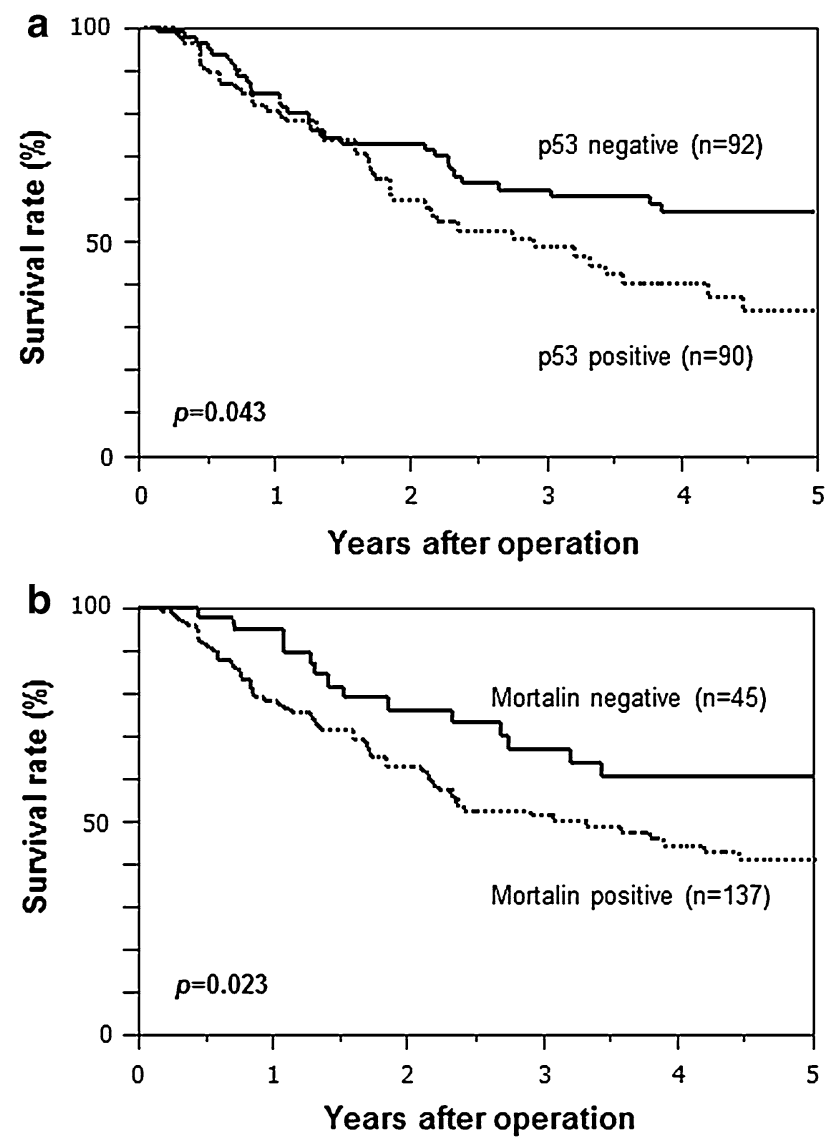

Fig. 2 Cumulative survival curve for gastric cancer patients. a Survival curve for gastric cancer patients in accordance with p53 expression. Tumors with expression of aberrant positive p53 had worse prognosis than those with aberrant negative p53 $(n=182$, $P=0.043$ ). b Survival curve for gastric cancer patients in accordance with mortalin expression. Mortalin-positive tumors had worse prognosis than mortalin-negative tumors $(n=182, P=0.023)$ outcome compared with mortalin-negative tumors (Fig. 4; $P=0.017$ ). With multivariate analysis (Table 5), mortalin expression appeared to be an independent prognostic factor in gastric cancer with scattered staining of p53 $(P=0.013)$.

\section{Discussion}

In treating gastric cancer, the most commonly used regimens are combination chemotherapy consisting of a fluoropyrimidine (5-fluorouracil or oral fluoropyrimidine) plus a platinum agent with or without docetaxel or anthracyclines. Unlike colorectal cancer, there are few molecular therapies for gastric cancer. In this study, we found that mortalin was highly expressed in gastric cancer and had a high impact on gastric cancer with normal function of p53. Targeting mortalin might be a remedy for gastric cancer in normal p53.

Cancer cells live in a more stressful environment than normal cells do. Because their number is so high, their nutrient and oxygen levels are low. Under stressful conditions, such as DNA damage, UV irradiation, and hypoxia, p53 is phosphorylated or acetylated. The post-translationally modified p53 is an activated form and translates its downstream factors such as $p 21, B A X$, PUMA, and Noxa [20-23]. This process causes cell cycle arrest (via p21) or apoptosis. Under normal conditions, p53 is unstable because its half-life is no longer than $20 \mathrm{~min}$ owing to cleavage through Mdm2 [24]. Once p53 has been phosphorylated, however, Mdm2 can no longer bind to p53, and activated p53 becomes stable. In cancer, $>50 \%$ of tumors have a mutation in the TP53 gene [25, 26], or Mdm2 is overexpressed [24] by its gene amplification, and normal function of p53 is thus inactivated. We evaluated the expression of Mdm2 in the same sample of gastric cancer used in this study. However, no relation between Mdm2 expression and p53 was observed (data not shown). Although p53 is recognized as an important factor for
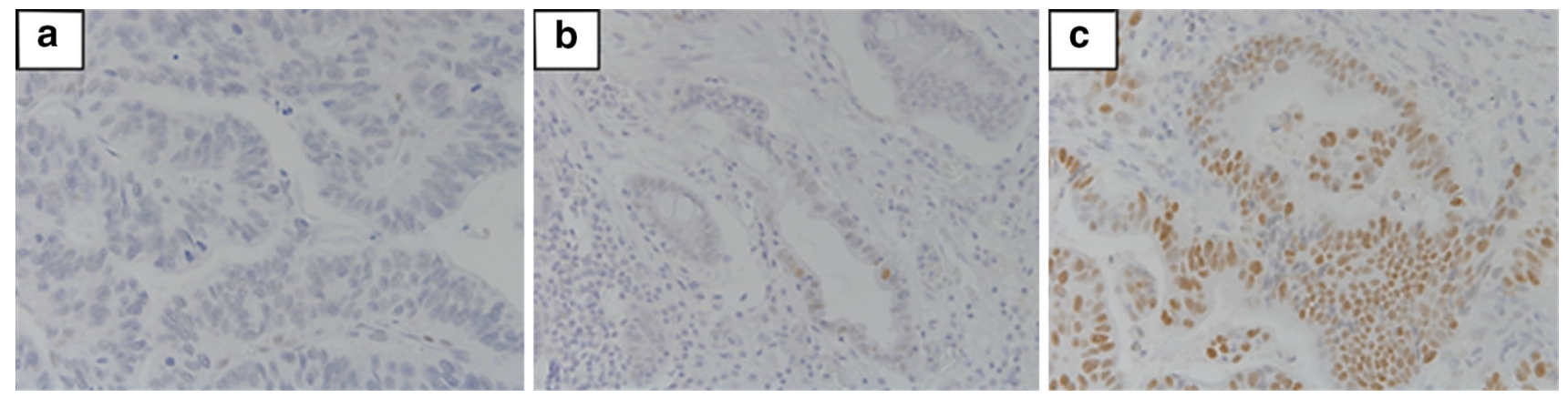

Fig. 3 Classification for p53 staining in gastric cancer. a Staining pattern of tumors with "null" staining of p53 (magnification, $\times 400$ ). b Staining pattern of tumors with "scattered" staining of p53 (magnification, $\times 400$ ). Single cells are stained sporadically. c Staining pattern of tumors with "aberrant" staining of p53 (magnification, $\times 400$ ). All cells are stained widely 
Table 2 Relation between p53 expression and TP53 gene status in gastric cancer

\begin{tabular}{lccc}
\hline & \multicolumn{2}{l}{$T P 53$ gene status } & $P$ value \\
\cline { 2 - 3 } & $\begin{array}{l}\text { Wild } \\
(\mathrm{n}=73)\end{array}$ & $\begin{array}{l}\text { Mutation } \\
(\mathrm{n}=17)(\%)\end{array}$ & \\
\hline p53 expression & & & $<0.0001$ \\
Null $(n=13)$ & $7(9.6)$ & $6(35.3)$ & \\
Scattered $(n=45)$ & $45(61.6)$ & $0(0)$ & \\
Aberrant $(n=32)$ & $21(28.8)$ & $11(64.7)$ & \\
\hline
\end{tabular}

Table 3 Relation between mortalin and p53 expression in gastric cancer

\begin{tabular}{llll}
\hline & $\begin{array}{l}\text { Mortalin expression } \\
\text { Negative }(n=45)\end{array}$ & $\begin{array}{l}\text { Positive } \\
(n=137)(\%)\end{array}$ & $P$ value \\
\hline p53 expression & $35(77.8)$ & $57(41.6)$ & $<0.0001$ \\
$\begin{array}{l}\text { Negative } \\
(n=92)\end{array}$ & $80(58.4)$ & \\
Positive $(n=90)$ & $10(22.2)$ & & \\
\hline
\end{tabular}

tumor suppression, its relationship with prognosis in cancer is controversial. Even large studies of TP53 gene in colorectal cancer have not been able to establish the relationship between TP53 gene mutation and prognosis [27, 28].

Mortalin is a member of the heat-non-inducible heat shock protein 70 family [29]. It is expressed under stressful conditions. Mortalin binds to and disrupts the function of p53 by inhibiting its entry into the nuclei $[10,11]$. It seems reasonable for cancer cells to express mortalin to protect them against stressful conditions, avoid tumor suppressor p53 function, and prevent apoptosis.

In gastric cancer clinical samples, mortalin-positive and aberrant p53 tumors had more malignant features and poorer prognosis compared with mortalin-negative or aberrant p53 negative tumors. Mortalin and aberrant p53 expression had a significant relationship, and tumor cells that were positive for mortalin also expressed aberrant $\mathrm{p} 53$. Aberrant p53 accumulated in the nuclei, which could have resulted in more malignant features. It is known that mortalin is expressed under stressful conditions [4-6]. In cancer cells with aberrant p53, the normal function of p53 is disrupted, and these cancer cells do not undergo apoptosis under stressful conditions. In these cancer cells, a stressed condition might influence mortalin expression by gene copy number gains or epigenetically function (e.g., hypo-methylation). This alteration of mortalin expression may prevent apoptosis.

The most notable finding in this study is that mortalin expression resulted in malignant features in gastric cancer
Table 4 Mortalin expression and clinicopathological factors in gastric cancer patients with scattered p53 expression

\begin{tabular}{|c|c|c|c|}
\hline \multirow[t]{2}{*}{ Factors } & \multicolumn{2}{|c|}{ Mortalin expression } & \multirow[t]{2}{*}{$P$-value } \\
\hline & $\begin{array}{l}\text { Negative } \\
(n=27)\end{array}$ & $\begin{array}{l}\text { Positive } \\
(n=48)(\%)\end{array}$ & \\
\hline Age (meant \pm SD) & $59.9 \pm 11.9$ & $64.8 \pm 12.7$ & 0.04 \\
\hline \multicolumn{4}{|l|}{ Gender } \\
\hline Male & $17(63.0)$ & $30(62.5)$ & \multirow[t]{2}{*}{0.96} \\
\hline Female & $10(37.0)$ & $18(37.5)$ & \\
\hline \multicolumn{4}{|l|}{ Differentiation } \\
\hline Differentiated & $11(40.7)$ & $16(33.3)$ & \multirow[t]{2}{*}{0.52} \\
\hline Undifferentiated & $16(59.3)$ & $32(66.7)$ & \\
\hline \multicolumn{4}{|l|}{ Vascular involvement } \\
\hline V0 & $17(63.0)$ & $31(64.6)$ & \multirow[t]{4}{*}{0.81} \\
\hline V1 & $8(29.6)$ & $13(27.1)$ & \\
\hline V2 & $2(6.7)$ & $3(6.3)$ & \\
\hline V3 & $0(0)$ & $1(2.0)$ & \\
\hline \multicolumn{4}{|c|}{ Lymphatic involvement } \\
\hline Ly0 & $10(37.0)$ & $17(35.4)$ & \multirow[t]{4}{*}{0.81} \\
\hline Ly1 & $5(18.6)$ & $10(20.8)$ & \\
\hline Ly2 & $6(22.2)$ & $14(29.2)$ & \\
\hline Ly3 & $6(22.2)$ & 7 (14 6) & \\
\hline \multicolumn{4}{|l|}{ Depth of invasion } \\
\hline M, SM & $9(33.3)$ & $5(10.4)$ & \multirow[t]{2}{*}{$0.017 * *$} \\
\hline MP, SS, SE, SI & $18(66.7)$ & $43(89.6)$ & \\
\hline \multicolumn{4}{|c|}{ Lymph node metastasis } \\
\hline Negative & $14(51.9)$ & $16(33.3)$ & \multirow[t]{2}{*}{0.11} \\
\hline Positive & $13(48.1)$ & $32(66.7)$ & \\
\hline \multicolumn{4}{|l|}{ Stage } \\
\hline $\mathrm{I}+\mathrm{II}$ & $14(51.9)$ & $21(43.8)$ & \multirow[t]{2}{*}{0.49} \\
\hline III + IV & $13(48.1)$ & $27(56.2)$ & \\
\hline
\end{tabular}

$M$ mucosa, $S M$ submucosa, $M P$ muscularis propria, $S S$ subserosa, $S E$ penetration of serosa, $S I$ invasion of adjacent structures

** $\mathrm{P}<0.05$

with "scattered" p53 staining (Table 4; Fig. 4). This is suggested by the fact that mortalin expression was an independent prognostic factor in gastric cancer with "scattered" p53 staining (Table 5). In this study, we evaluated the significance of p53 immunohistochemistry staining in gastric cancer. By classifying the p53 staining pattern in three groups, we found that the "scattered" staining pattern of p53 reflected wild-type TP53 gene. This result was consistent with a previous report on colorectal cancer done by Kaserer et al. [17]. They reported that this scattered staining type in colorectal cancer cells represents a functionally active non-mutated p53 gene. We might therefore be able to distinguish normal p53 function by immunohistochemistry staining of p53. "Scattered" type reflects normal p53 function. 


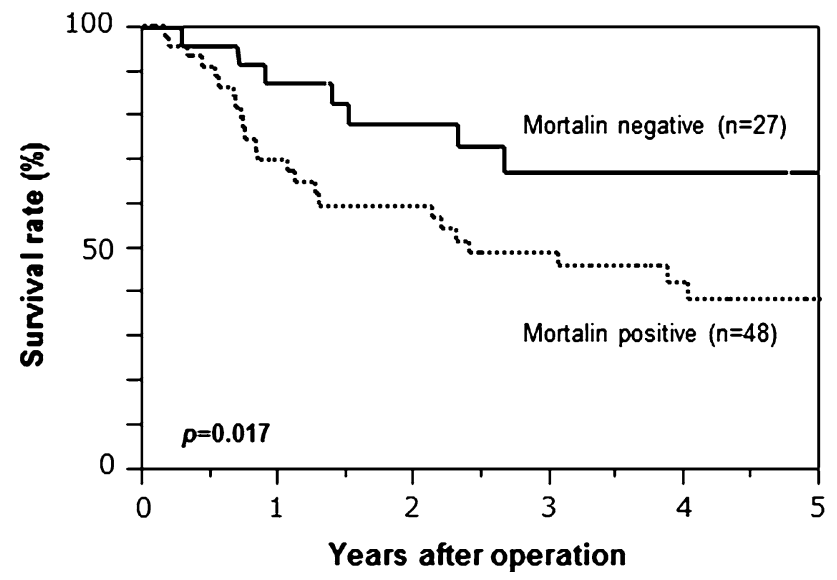

Fig. 4 Cumulative survival curve for gastric cancer patients with scattered p53 expression. Tumors with mortalin-positive expression had poor prognosis $(n=75, P=0.017)$

Table 5 Cox regression analysis for gastric cancer patients with scattered p53 expression

\begin{tabular}{lll}
\hline $\begin{array}{l}\text { Explanatory variable } \\
\text { (observed value) }\end{array}$ & $P$ value & $\begin{array}{l}\text { Relative risk (95\% } \\
\text { confidence interval) }\end{array}$ \\
\hline $\begin{array}{l}\text { Vascular involvement (none vs. } \\
\text { present) }\end{array}$ & 0.41 & $2.83(1.94-4.21)$ \\
$\begin{array}{l}\text { Lymphatic involvement (none } \\
\text { vs. present) }\end{array}$ & $0.01 *$ & $11.3(9.88-13.82)$ \\
$\begin{array}{l}\text { Lymph node metastasis (none } \\
\text { vs. present) }\end{array}$ & 0.21 & $1.56(1.25-3.08)$ \\
$\begin{array}{l}\text { Differentiation (differentiated } \\
\text { vs. undifferentiated) }\end{array}$ & $0.004^{*}$ & $8.22(5.98-8.58)$ \\
\begin{tabular}{l} 
Mortalin (negative vs. positive) \\
\hline
\end{tabular} & $0.013^{*}$ & $6.08(5.0-7.97)$ \\
\hline
\end{tabular}

* Statistically significant

From this study, we found that mortalin is crucial for malignant features, even in gastric cancer with normal p53. Our results suggest that mortalin expression is an independent prognostic factor in such gastric cancer. Mortalin is known to bind to p53 and to prevent the entry of p53 into the nucleus and disrupt its normal function. In gastric cancer with expression of normal p53, mortalin might disrupt normal p53 function as a tumor suppressor and benefit cancer cells. To treat gastric cancer that has mortalin expression, a drug that avoids mortalin and p53 binding could be useful. MKT-077 is a rhodacyanine dye analog that preferentially accumulates in tumor cells [30]. It has been reported that its selective toxicity to tumor cells is mediated by binding to mortalin and reactivation of p53 function [31]. Although a phase I trial of MKT-077 with chemoresistant solid tumors failed because of renal toxicity [32], there remains a possibility for using the drug in mortalin-expressing tumors. Deocaris et al. [33] have reported that in tumor cells with elevated mortalin expression, low doses of MKT-077 are sufficient to induce senescence and might prevent renal toxicity. In deciding on the usage of MKT-077, investigation of mortalin expression by immunohistochemical staining might be a useful tool. MKT-077 may be effective in gastric cancer with normal p53 and mortalin-positive expression.

Our results show that mortalin expression is a prognostic marker in gastric cancer, especially in tumors with normal p53 function. When choosing mortalin as a target molecule, p53 expression is a selective marker, which may result in effective therapy.

Acknowledgments We thank Ms. Y. Kubota for her preparation of the immunohistochemistry samples.

\section{References}

1. Wadhwa R, Kaul SC, Ikawa Y, Sugimoto Y. Identification of a novel member of mouse hsp70 family. Its association with cellular mortal phenotype. J Biol Chem. 1993;268:6615-21.

2. Kaul SC, Duncan E, Sugihara T, Reddel RR, Mitsui Y, Wadhwa R. Structurally and functionally distinct mouse hsp70 family members Mot-1 and Mot-2 proteins are encoded by two alleles. DNA Res. 2000;7:229-31.

3. Kaul SC, Duncan EL, Englezou A, Takano S, Reddel RR, Mitsui Y, Wadhwa R. Malignant transformation of NIH3T3 cells by overexpression of mot-2 protein. Oncogene. 1998;17:907-11.

4. Liu Y, Liu W, Song XD, Zuo J. Effect of GRP75/mthsp70/ PBP74/mortalin overexpression on intracellular ATP level, mitochondrial membrane potential and ROS accumulation following glucose deprivation in PC12 cells. Mol Cell Biochem. 2005;268:45-51.

5. Merrick BA, Walker VR, He C, Patterson RM, Selkirk JK. Induction of novel Grp75 isoforms by 2-deoxyglucose in human and murine fibroblasts. Cancer Lett. 1997;119:185-90.

6. Sadekova S, Lehnert S, Chow TY. Induction of PBP74/mortalin/ Grp75, a member of the hsp70 family, by low doses of ionizing radiation: a possible role in induced radioresistance. Int J Radiat Biol. 1997;72:653-60.

7. Mizukoshi E, Suzuki M, Loupatov A, Uruno T, Hayashi H, Misono T, Kaul SC, Wadhwa R, Imamura T. Fibroblast growth factor-1 interacts with the glucose-regulated protein GRP75/ mortalin. Biochem J. 1999;343(Pt 2):461-6.

8. Takano S, Wadhwa R, Mitsui Y, Kaul SC. Identification and characterization of molecular interactions between glucose-regulated proteins (GRPs) mortalin/GRP75/peptide-binding protein 74 (PBP74) and GRP94. Biochem J. 2001;357:393-8.

9. Wadhwa R, Yaguchi T, Hasan MK, Taira K, Kaul SC. MortalinMPD (mevalonate pyrophosphate decarboxylase) interactions and their role in control of cellular proliferation. Biochem Biophys Res Commun. 2003;302:735-42.

10. Wadhwa R, Takano S, Robert M, Yoshida A, Nomura H, Reddel RR, Mitsui Y, Kaul SC. Inactivation of tumor suppressor p53 by mot-2, a hsp70 family member. J Biol Chem. 1998;273: 29586-91.

11. Wadhwa R, Yaguchi T, Hasan MK, Mitsui Y, Reddel RR, Kaul SC. Hsp70 family member, mot-2/mthsp70/GRP75, binds to the cytoplasmic sequestration domain of the p53 protein. Exp Cell Res. 2002;274:246-53.

12. Wadhwa R, Takano S, Kaur K, Deocaris CC, Pereira-Smith OM, Reddel RR, Kaul SC. Upregulation of mortalin/mthsp70/Grp75 
contributes to human carcinogenesis. Int J Cancer. 2006;118: 2973-80.

13. Wadhwa R, Takano S, Taira K, Kaul SC. Reduction in mortalin level by its antisense expression causes senescence-like growth arrest in human immortalized cells. J Gene Med. 2004;6:439-44.

14. Dundas SR, Lawrie LC, Rooney PH, Murray GI. Mortalin is over-expressed by colorectal adenocarcinomas and correlates with poor survival. J Pathol. 2005;205:74-81.

15. Aikou T, Hokita $S$, Natsugoe S. Japanese classification of gastric carcinoma (the 13th edition, June 1999): points to be revised. Nippon Rinsho. 2001;59(Suppl 4):159-65.

16. Elledge RM, Clark GM, Fuqua SA, Yu YY, Allred DC. p53 protein accumulation detected by five different antibodies: relationship to prognosis and heat shock protein 70 in breast cancer. Cancer Res. 1994;54:3752-7.

17. Kaserer K, Schmaus J, Bethge U, Migschitz B, Fasching S, Walch A, Herbst F, Teleky B, Wrba F. Staining patterns of p53 immunohistochemistry and their biological significance in colorectal cancer. J Pathol. 2000;190:450-6.

18. Rodrigues NR, Rowan A, Smith ME, Kerr IB, Bodmer WF, Gannon JV, Lane DP. p53 mutations in colorectal cancer. Proc Natl Acad Sci USA. 1990;87:7555-9.

19. Sumiyoshi Y, Kakeji Y, Egashira A, Mizokami K, Orita H, Maehara Y. Overexpression of hypoxia-inducible factor 1alpha and p53 is a marker for an unfavorable prognosis in gastric cancer. Clin Cancer Res. 2006;12:5112-7.

20. el-Deiry WS, Kern SE, Pietenpol JA, Kinzler KW, Vogelstein B. Definition of a consensus binding site for p53. Nat Genet. 1992; $1: 45-9$.

21. Miyashita T, Reed JC. Tumor suppressor p53 is a direct transcriptional activator of the human bax gene. Cell. 1995;80:293-9.

22. Nakano K, Vousden KH. PUMA, a novel proapoptotic gene, is induced by p53. Mol Cell. 2001;7:683-94.

23. Oda E, Ohki R, Murasawa H, Nemoto J, Shibue T, Yamashita T, Tokino T, Taniguchi T, Tanaka N. Noxa, a BH3-only member of the Bcl-2 family and candidate mediator of p53-induced apoptosis. Science. 2000;288:1053-8.
24. Momand J, Zambetti GP, Olson DC, George D, Levine AJ. The mdm-2 oncogene product forms a complex with the p53 protein and inhibits p53-mediated transactivation. Cell. 1992;69: $1237-45$.

25. Beroud C, Soussi T. The UMD-p53 database: new mutations and analysis tools. Hum Mutat. 2003;21:176-81.

26. Hussain SP, Harris CC. Molecular epidemiology of human cancer: contribution of mutation spectra studies of tumor suppressor genes. Cancer Res. 1998;58:4023-37.

27. Munro AJ, Lain S, Lane DP. P53 abnormalities and outcomes in colorectal cancer: a systematic review. Br J Cancer. 2005;92: 434-44.

28. Russo A, Bazan V, Iacopetta B, Kerr D, Soussi T, Gebbia N. The TP53 colorectal cancer international collaborative study on the prognostic and predictive significance of p53 mutation: influence of tumor site, type of mutation, and adjuvant treatment. J Clin Oncol. 2005;23:7518-28.

29. Kaul SC, Deocaris CC, Wadhwa R. Three faces of mortalin: a housekeeper, guardian and killer. Exp Gerontol. 2007;42:263-74.

30. Koya K, Li Y, Wang H, Ukai T, Tatsuta N, Kawakami M, Shishido T, Chen LB. MKT-077, a novel rhodacyanine dye in clinical trials, exhibits anticarcinoma activity in preclinical studies based on selective mitochondrial accumulation. Cancer Res. 1996;56:538-43.

31. Wadhwa R, Sugihara T, Yoshida A, Nomura H, Reddel RR, Simpson R, Maruta H, Kaul SC. Selective toxicity of MKT-077 to cancer cells is mediated by its binding to the hsp70 family protein mot-2 and reactivation of p53 function. Cancer Res. 2000;60:6818-21.

32. Propper DJ, Braybrooke JP, Taylor DJ, Lodi R, Styles P, Cramer JA, Collins WC, Levitt NC, Talbot DC, Ganesan TS, Harris AL. Phase I trial of the selective mitochondrial toxin MKT077 in chemo-resistant solid tumours. Ann Oncol. 1999;10:923-7.

33. Deocaris CC, Widodo N, Shrestha BG, Kaur K, Ohtaka M, Yamasaki K, Kaul SC, Wadhwa R. Mortalin sensitizes human cancer cells to MKT-077-induced senescence. Cancer Lett. 2007;252:259-69. 